\title{
Histological alterations in the liver of sea bream, Sparus aurata L., caused by short- or long-term feeding with vegetable oils. Recovery of normal morphology after feeding fish oil as the sole lipid source
}

\author{
M J Caballero', M S Izquierdo', E Kjørsvik ${ }^{2}$, A J Fernández ${ }^{3}$ and G Rosenlund ${ }^{4}$ \\ 1 GIA, Instituto Canario de Ciencias Marinas, Telde, Las Palmas de Gran Canaria, Canary Islands, Spain \\ 2 Department of Zoology, Brattøra Research Center, Trondheim, Norway \\ 3 Departamento de Morfología, Facultad de Veterinaria, Arucas, Las Palmas de Gran Canaria, Canary Islands, Spain \\ 4 Nutreco Aquaculture Research Centre A/S, Stavanger, Norway
}

\begin{abstract}
This study evaluated the effects of fish oil (FO) replacement by vegetable oils [soybean oil (SO), rapeseed oil (RO), linseed oil (LO)] and subsequent feeding with $\mathrm{FO}$ on the liver morphology of sea bream. A short-term trial (3 months) and longterm trial (6 months) were carried out feeding sea bream with the following experimental diets: FO100\%; $\quad$ SO60 $\%+$ FO $40 \% ; \quad$ RO60 $\%+$ FO $40 \% ; \quad$ LO60\% + FO40\%; $\quad \mathrm{SO}+\mathrm{RO}+$ $\mathrm{LO} 60 \%+\mathrm{FO} 40 \%$. Finally, all groups from the long-term trial were fed with $\mathrm{FO} 100 \%$ for 95 days (washout period). Liver samples were taken for histological and biochemical studies. In both the short- and long-term trials, livers of sea bream fed $\mathrm{LO} 60 \%$ and $\mathrm{SO}+\mathrm{RO}+\mathrm{LO} 60 \%$ showed a similar hepatic morphology to that observed in fish fed FO100\%. In contrast, sea bream fed SO60\% showed an intense steatosis, with foci of swollen hepatocytes containing numerous lipid vacuoles. After the washout period, a considerable reduction of the cytoplasmic vacuolation and the lipid vacuole accumulation were observed in the livers of fish fed the different experimental diets. The results of this study suggested that the type of non-essential fatty acid, characteristic of vegetable oils, induces the appearance of steatosis in the following order:
\end{abstract}

Correspondence $\operatorname{Dr} M J$ Caballero, GIA, Instituto Canario de Ciencias Marinas, ULPGC, PO Box 56, 35200, Telde, Las Palmas de Gran Canaria, Canary Islands, Spain

(e-mail: mjcaballero@iccm.rcanaria.es) linoleic acid $>$ linolenic acid $>$ oleic acid. However, the liver alterations found during the experimental periods with vegetable oils are reversible when the fish are re-fed with a balanced diet (FO100\%), indicating the non-pathological character of these histological changes.

Keywords: hepatic morphology, histology, lipid metabolism, nutritional pathology, sea bream, vegetable oils.

\section{Introduction}

The increasing global demand for fish oil (FO) and the unpredictability of its production may require the use of vegetable oils in commercial aquafeeds (FAO 1997). Partial replacement of FO by certain vegetable oils has proved feasible in several species without affecting growth (Caballero, Obach, Rosenlund, Montero, Gisvold \& Izquierdo 2002; Bell, McGhee, Campbell \& Sargent 2003; Izquierdo, Obach, Arantzamendi, Montero, Robaina \& Rosenlund 2003; Regost, Arzel, Robien, Rosenlund \& Kaushik 2003). However, the effects of these oils on lipid metabolism and health of fish still remain unclear, particularly in marine fish where fish meal and oil provide the only source of highly unsaturated fatty acids, essential for these species. Dietary inclusion of vegetable oils may lead to imbalances in the essential or non-essential fatty acids, affecting tissue integrity.

Lipid metabolism is mainly regulated by the liver, including both the synthesis and degradation of fatty 
acids, and several enzymes regulating these pathways show varying affinities for the different fatty acids available in the organ (Kiessling \& Kiessling 1993; Henderson 1996), thus imbalances in the dietary fatty acids could modify the functioning and morphology of this organ. In addition, liver functions as a main energy reservoir, frequently in the form of triacylglycerols (TGs), in certain species such as cod (Lie, Lied \& Lambertsen 1986), sea bream or seabass (Kaushik 1997). Thus, when dietary lipid or energy exceed the capacity of the hepatic cells to oxidize fatty acids, or when protein synthesis is impaired, the result is the large synthesis and deposition of TG in vacuoles, leading to a morphological pattern known as steatosis. Liver steatosis has been frequently observed associated with nutritional imbalances in cultured fish (Tacon 1996). In sea bream, steatosis has been observed as a result of an increase in the dietary lipid content (Caballero, López-Calero, Socorro, Roo, Izquierdo \& Fernández 1999), an essential fatty acid deficiency (Montero, Robaina, Socorro, Vergara, Tort \& Izquierdo 2001), the use of artificial diets (Spisni, Tugnoli, Ponticelli, Mordenti \& Tomasi 1998) and the inclusion of vegetable oils (Alexis 1997), although its effect in the correct functioning of the liver and its possible reversibility is not well understood. Whereas some authors consider steatosis as a physiological adaptation to the diet (Segner \& Witt 1990; Caballero et al. 1999), others stress the pathological significance of steatosis (Mosconi-bac 1990), even if necrosis or cellular damage is not found, arguing that longer periods of feeding would irreversibly damage the tissue.

Gilthead sea bream, Sparus aurata L., is the most important marine fish species in Mediterranean aquaculture. High-energy commercial feeds cause large lipid accumulations in the liver of this species which is of concern to fish producers. Thus, the objectives of this study were to compare the effect of low and high levels of vegetable oils in practical diets for sea bream, to determine the effects of long-term feeding of such diets on the progression of liver steatosis, and on the ability of the fish to recover the initial liver morphology after a washout period of feeding FO after feeding with vegetable oils.

\section{Materials and methods}

\section{Fish}

The experiments were carried out at the Instituto Canario de Ciencias Marinas (Canary Islands,
Spain) and all fish were obtained from a local fish farm (ADSA, San Bartolomé de Tirajana, Canary Islands, Spain). A short-term trial was carried out with gilthead sea bream for 101 days. A total of 300 gilthead sea bream of $10.06 \mathrm{~g}$ mean initial body weight were randomly distributed in $100 \mathrm{~L}$ polyethylene circular tanks (20 fish/tank). Tanks were supplied with continuous sea water $(36 \%)$ flow and aeration. Fish were fed under natural photoperiod conditions of approximately $12 \mathrm{~h}$ light $/ 12 \mathrm{~h}$ darkness. Water temperature and dissolved oxygen during the experimental period ranged between 20.0 and $24.2^{\circ} \mathrm{C}$ and 5.04 and $8.32 \mathrm{mg} \mathrm{L}^{-1}$. Fish were acclimatized to the experimental tanks and fed the control diet for 2 weeks before the beginning of the experiment. They were fed the experimental diets until apparent satiation three times a day, at $9.00,12.00$ and 15.00 hours, 6 days per week. Each diet was assayed in triplicate. Samples of liver were taken for histology and biochemical composition.

A long-term trial was carried out on gilthead sea bream for 6 months. A total of 1560 gilthead sea bream juveniles of $79 \pm 8.0 \mathrm{~g}$ mean initial body weight were distributed in $24500 \mathrm{~L}$ fibreglass tanks in groups of 65 fish. Each tank was provided with continuous sea water and air flows. During the experiment, water temperature ranged between 21 and $24{ }^{\circ} \mathrm{C}$ and dissolved oxygen between 6.0 and $8.0 \mathrm{mg} \mathrm{L}^{-1}$. Fish were subjected to a natural photoperiod of approximately $12 \mathrm{~h}$ light $/ 12 \mathrm{~h}$ darkness. Fish were fed a commercial diet (Proaqua S.A., Dueñas, Spain) for 2 weeks to allow acclimatization to the culture system before the feeding trial started. Fish were fed to apparent satiation three times a day, 6 days a week for 6 months until they reached a final body weight of about $450 \mathrm{~g}$, which is a standard commercial size for the Mediterranean market. The experimental diets were fed to triplicate groups of fish. Samples of liver were taken for histology at the intermediate (3 months) and the end of the experimental period (6 months). Subsequently, all the remaining fish fed the different experimental diets were fed only the control diet (100\% FO) for 95 days (washout period).

\section{Experimental diets}

For the short-term trial, five isoenergetic and isoproteic (46\%) experimental diets were formulated with a constant lipid content of about $25 \%$. Extruded diets were produced as 2 and $3 \mathrm{~mm}$ pellets by 
Table 1 Composition $\left(\mathrm{g} \mathrm{kg}^{-1}\right)$ of experimental diets containing different lipid sources and used in short-term feeding trial for gilthead sea bream

\begin{tabular}{|c|c|c|c|c|c|}
\hline \multirow[b]{2}{*}{ Ingredient } & \multicolumn{5}{|l|}{ Diet } \\
\hline & FO & SO & RO & LO & Mix \\
\hline Fish meal (LT) & 361.3 & 361.3 & 361.3 & 361.3 & 361.3 \\
\hline Corn gluten & 259.8 & 259.8 & 259.8 & 259.8 & 259.8 \\
\hline Wheat & 165.0 & 165.0 & 165.0 & 165.0 & 165.0 \\
\hline Lysine (99\%) & 7.2 & 7.2 & 7.2 & 7.2 & 7.2 \\
\hline Premix ${ }^{a}$ & 10.0 & 10.0 & 10.0 & 10.0 & 10.0 \\
\hline Anchovy oil & 196.7 & 78.7 & 78.7 & 78.7 & 78.7 \\
\hline Soybean oil ${ }^{\mathrm{b}}$ & & 118.0 & & & 11.8 \\
\hline Rapeseed oil ${ }^{b}$ & & & 118.0 & & 35.4 \\
\hline Linseed oil $^{\mathrm{b}}$ & & & & 118.0 & 70.8 \\
\hline
\end{tabular}

${ }^{a}$ Premix of vitamins and minerals according to NRC recommendations for fish also including yttrium oxide $\left(0.2 \mathrm{~g} \mathrm{~kg}^{-1}\right.$ diet $)$ as inert marker for digestibility measurements.

${ }^{\mathrm{b}}$ Crude vegetable oils.

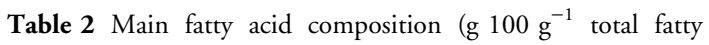
acids) of diets containing fish oil in combination with different vegetable lipid sources used in short-term feeding trial for gilthead sea bream

\begin{tabular}{lrrrrr}
\hline & Diet & & & & \\
\cline { 2 - 6 } & FO & \multicolumn{1}{c}{ SO } & RO & LO & Mix \\
\hline 16:0 & 15.5 & 13.4 & 11.3 & 11.0 & 11.2 \\
18:1n-9 & 11.4 & 14.4 & 27.8 & 15.1 & 17.8 \\
18:2n-6 & 7.3 & 26.2 & 16.0 & 13.0 & 14.6 \\
18:3n-3 & 3.8 & 4.7 & 5.2 & 23.0 & 18.2 \\
20:4n-6 & 0.6 & 0.4 & 0.3 & 0.3 & 0.3 \\
20:5n-3 & 13.9 & 8.1 & 7.5 & 7.3 & 7.3 \\
22:6n-3 & 8.9 & 5.6 & 5.4 & 5.3 & 5.4 \\
Saturated & 25.0 & 20.9 & 17.8 & 17.6 & 17.8 \\
Monounsaturated & 25.9 & 24.8 & 39.5 & 25.1 & 28.2 \\
n-3 & 31.2 & 21.3 & 20.7 & 38.2 & 33.4 \\
n-6 & 9.4 & 27.5 & 17.2 & 14.1 & 15.7 \\
n-9 & 14.2 & 16.7 & 30.9 & 17.7 & 20.5 \\
n-3/n-6 & 3.3 & 0.8 & 1.2 & 2.7 & 2.1 \\
n-3 HUFA & 25.2 & 15.2 & 14.2 & 13.9 & 14.0 \\
n-3 HUFA (\% d.w.) & 6.7 & 3.5 & 3.7 & 3.7 & 4.0 \\
Lipids (\% d.w.) & 26.7 & 23.2 & 25.8 & 26.6 & 28.5 \\
\hline
\end{tabular}

Nutreco ARC (Stavanger, Norway). Anchovy oil was the only lipid source added in the control diet (FO diet) (Table 1). Anchovy oil was included in the other experimental diets at a level high enough ( $40 \%$ of FO diet) to keep the n-3 HUFA levels well over $3 \%$ in order to cover the essential fatty acid requirements of this species (Montero, Tort, Izquierdo, Socorro, Robaina, Vergara \& Fernández-Palacios 1996). Thus, whereas the FO diet contained $6.71 \% \mathrm{n}-3$ HUFA on a dry weight basis, the other experimental diets contained from 3.5 to $4 \%$ (Table 2). Soybean oil (SO), rapeseed oil (RO), linseed oil (LO) and a combination of the three vegetable oils were used in
Table 3 Composition $\left(\mathrm{g} \mathrm{kg}^{-1}\right)$ of experimental diets containing different lipid sources and used in long-term feeding trial for gilthead sea bream

\begin{tabular}{|c|c|c|c|c|c|c|}
\hline \multirow[b]{2}{*}{ Ingredient } & \multicolumn{6}{|l|}{ Diet } \\
\hline & $100 \mathrm{FO}$ & $60 \mathrm{SO}$ & $60 R O$ & 60LO & $80 \mathrm{SO}$ & 80LO \\
\hline Fish meal (LT) & 381 & 381 & 381 & 381 & 381 & 381 \\
\hline Corn gluten & 260 & 260 & 260 & 260 & 260 & 260 \\
\hline Wheat & 150.6 & 150.6 & 150.6 & 150.6 & 150.6 & 150.6 \\
\hline Lysine (99\%) & 7.23 & 7.23 & 7.23 & 7.23 & 7.23 & 7.23 \\
\hline Premix $^{a}$ & 25 & 25 & 25 & 25 & 25 & 25 \\
\hline Anchovy oil & 176 & 70.4 & 70.4 & 70.4 & 35.2 & 35.2 \\
\hline Soybean oil ${ }^{\mathrm{b}}$ & & 105.6 & & & 140.8 & \\
\hline Rapeseed oil ${ }^{b}$ & & & 105.6 & & & \\
\hline Linseed oil ${ }^{b}$ & & & & 105.6 & & 140.8 \\
\hline
\end{tabular}

${ }^{a}$ Premix of vitamins and minerals according to NRC (1993) recommendations for fish.

${ }^{\mathrm{b}}$ Crude vegetable oils.

the diets SO, RO, LO and Mix, respectively, as complementary lipid sources to replace $60 \%$ of the FO used in the FO diet. Mainly due to the different linoleic acid contents of the plant oils used, the $n-3 /$ n- 6 ratio markedly differed among the experimental diets, ranging from 0.8 in the $\mathrm{SO}$ diet to 3.3 in the $\mathrm{FO}$ diet (Table 2).

For the long-term trial, five experimental diets were formulated to be isoenergetic and isonitrogenous containing $22 \%$ crude lipid and $45 \%$ crude protein. While the control diet (100FO diet) contained anchovy oil as the only added lipid source, in all the other diets anchovy oil was partly replaced by vegetable oils (Table 3 ). Sixty per cent of anchovy oil was replaced by either SO, RO or $\mathrm{LO}$ in diets $60 \mathrm{SO}, 60 \mathrm{RO}$ and $60 \mathrm{LO}$ whereas $80 \%$ was replaced by either $\mathrm{SO}$ or $\mathrm{LO}$ in diets $80 \mathrm{SO}$ and 80LO. Anchovy oil was included in all diets at a level high enough to keep the n-3 HUFA content over $3 \%$ in order to meet the essential fatty acid requirements of this species (Montero et al. 1996). Analysis of the fatty acid composition of the diets (Table 4) showed the highest saturated fatty acid and n-3 HUFA content in diet 100FO, highest linoleic acid (18:2n-6) in diets $60 \mathrm{SO}$ and 80SO, highest linolenic acid (18:3n-3) in diets 60LO and 80LO and highest oleic acid (18:1n-9) in diet 60RO. Dietary ratios of n-3/n-6 differed among the experimental diets mainly due to the different 18:2n-6 content of the plant oils used, ranging from 1.4 in diet $100 \mathrm{FO}$, to 0.5 in diet $60 \mathrm{SO}$ and 0.3 in diet $80 \mathrm{SO}$. Diets $60 \mathrm{LO}$ and $80 \mathrm{LO}$ had an $\mathrm{n}-3 / \mathrm{n}-6$ ratio higher than 2 , mainly due to the higher $18: 3 n-3$ content. Diets $80 S O$ 


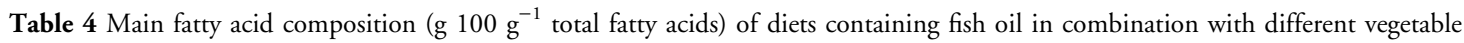
lipid sources used in long-term feeding trial for gilthead sea bream

\begin{tabular}{|c|c|c|c|c|c|c|c|}
\hline & \multicolumn{7}{|l|}{ Diet } \\
\hline & 100FO & 6050 & $60 R O$ & 60LO & $60 \mathrm{Mix}$ & 8050 & 80LO \\
\hline $16: 0$ & 18.51 & 15.45 & 12.43 & 12.21 & 13.37 & 14.24 & 10.89 \\
\hline $18: 1 n-9$ & 16.26 & 18.48 & 36.84 & 17.03 & 23.40 & 21.07 & 18.71 \\
\hline $18: 2 n-6$ & 13.07 & 31.28 & 17.04 & 12.29 & 15.29 & 38.54 & 17.66 \\
\hline $18: 3 n-3$ & 1.41 & 3.24 & 4.64 & 26.72 & 18.27 & 4.03 & 30.63 \\
\hline $20: 4 n-6$ & 0.54 & 0.34 & 0.33 & 0.36 & 0.31 & 0.25 & 0.23 \\
\hline $20: 5 n-3$ & 11.19 & 5.88 & 5.84 & 6.19 & 5.10 & 3.73 & 3.79 \\
\hline $22: 6 n-3$ & 4.99 & 3.20 & 3.26 & 3.58 & 2.83 & 2.36 & 2.92 \\
\hline Saturated & 27.9 & 21.84 & 17.89 & 18.67 & 19.94 & 18.64 & 16.28 \\
\hline Monounsaturated & 30.45 & 27.70 & 45.10 & 26.24 & 32.92 & 27.17 & 24.63 \\
\hline$n-3$ & 22.65 & 15.14 & 16.36 & 39.33 & 28.51 & 11.86 & 39.04 \\
\hline$n-6$ & 15.75 & 32.88 & 18.50 & 13.81 & 16.71 & 39.61 & 18.69 \\
\hline$n-9$ & 18.29 & 20.33 & 38.95 & 18.64 & 25.30 & 22.59 & 20.40 \\
\hline$n-3 / n-6$ & 1.44 & 0.46 & 0.88 & 2.85 & 1.71 & 0.30 & 2.09 \\
\hline n-3 HUFA & 17.96 & 10.23 & 10.11 & 10.95 & 8.84 & 6.91 & 7.43 \\
\hline n-3 HUFA (\% d.w.) & 3.8 & 2.1 & 2.2 & 2.4 & 2.0 & 1.4 & 1.7 \\
\hline Lipids (\% d.w.) & 21.14 & 20.70 & 21.83 & 21.83 & 22.38 & 20.93 & 22.58 \\
\hline
\end{tabular}

and 80LO had the lowest n-3 HUFA content, particularly in arachidonic acid (20:4n-6) (ARA), eicosapentaenoic acid (20:5n-3) (EPA) and docosahexaenoic acid (22:6n-3) (DHA).

\section{Tissue processing for microscopy}

For the short-term trial, four livers per tank were collected and dissected into small pieces and fixed at $4{ }^{\circ} \mathrm{C}$ in $2.5 \%$ glutaraldehyde in $0.2 \mathrm{M}$ phosphate buffer $(\mathrm{pH}$ 7.2). The pieces were then rinsed in phosphate buffer and post-fixed for $1 \mathrm{~h}$ in $2 \%$ osmium tetraoxide in $0.2 \mathrm{~m}$ imidazole buffer. They were then contrasted in 1.5\% uranyl acetate and dehydrated in ethanol and propylene oxide before embedding in Epon/Aradilte (Angermüller \& Dariush Fahimi 1982). For each sampled fish, two blocks were taken at random. Serial semi-thin sections $(1 \mu \mathrm{m})$ were stained with toluidine blue and basic fuschin (TB\&BF) (Hoffman, Flores, Coover \& Garrett 1983) and examined under light microscopy.

For the long-term and washout trials, four livers per tank were collected. Samples were fixed in $10 \%$ buffered formalin, dehydrated in a graded ethanol series and embedded in paraffin. Serial $4 \mu \mathrm{m}$ sections were stained with haematoxylin and eosin (H\&E) (Martoja \& Martoja-Pierson 1970). Evaluation of histological changes (nuclear displacement, cytoplasm vacuolization and infiltration of peripancreatic fat) was carried out using a fourgraded examination scheme: $0=$ not observed; $1=$ few; $2=$ medium; $3=$ severe.

\section{Stereological analyses of liver}

Stereological analyses were performed using the point counting method of Weibel (1979). Volume density was estimated by placing a lattice of test points $\left(P_{\mathrm{T}}\right)$ on micrographs and by determining the number of these points $\left(P_{\mathrm{Pi}_{\mathrm{i}}}\right)$ enclosed within profiles of the structure investigated. The volume density $V_{\mathrm{Vi}}$ was calculated from $V_{\mathrm{Vi}}=P_{\mathrm{Pi}_{\mathrm{i}}} / P_{\mathrm{T}}$. Test points falling on extracellular space were subtracted from the total number of test points.

Volume density of hepatic lipid was determined on light micrographs $(\times 400, T B \& B F)$ using a test point with 322 systematically spaced points at a distance of $d=5 \mathrm{~mm}$ (corresponding to $15 \mu \mathrm{m})$.

\section{Biochemical analyses of the diets and liver}

Lipids of diets and liver were extracted with a chloroform:methanol (2:1, v:v) mixture as described by Folch, Lees \& Sloane-Stanley (1957). The fatty acid methyl esters were obtained by transesterification with $1 \%$ sulphuric acid in methanol (Christie 1982) using heneicosaenoic acid (10\% of total lipids) as internal standard. Fatty acid methyl esters were purified by absorption chromatography on $\mathrm{NH}_{2}$ sep-pack cartridges (Waters, S.A., Milford, MA, USA) as described by Fox (1990), and separated and quantified by gas-liquid chromatography following the conditions described by Izquierdo, Watanabe, Takeuchi, Arakawa \& Kitajima (1990). 


\section{Statistical analysis}

All data were statistically treated using ANOVA and Tukey's multiple range test $(P<0.05)$ (Sokal \& Rolf 1995).

\section{Results}

\section{Growth}

In the short-term trial, sea bream grew to a final average body weight of $64 \mathrm{~g}$. No significant differences were found in mean body weights during the experimental period (Table 5). In the long-term trial, growth of sea bream fed diets $80 \mathrm{SO}$ and $80 \mathrm{LO}$ was significantly $(P<0.05)$ lower than that of sea bream fed the FO diet (Table 6). No clinical disease or mortalities were detected during the experimental periods.

\section{Histological examination and stereological analyses of livers after short-term feeding trial}

Liver of sea bream fed the FO diet showed regularshaped hepatocytes with large centrally located nuclei and some lipid vacuoles in the cytoplasm which did not significantly affect the size of the hepatocytes (Fig. 1a). Similarly, livers of sea bream fed diets LO (Fig. 1b) and Mix had hepatocytes which were homogeneous in size with vacuolated cytoplasm. Sea bream fed diet RO showed few lipid vacuoles in the cytoplasm (Fig. 1c). In contrast, sea bream fed diet SO had foci of steatosis with hepatocytes containing numerous varying-size lipid vacuoles (Fig. 1d).

Stereological results are shown in Table 7. The volume of hepatic lipid was significantly higher $(P<0.05)$ in those fish fed diet SO, whereas livers of fish fed diet RO showed a low lipid content, even smaller than that in fish fed the FO diet.

\section{Histological examination and visual evaluation of livers in the long-term feeding trial}

After 3 months of feeding with the different experimental diets, livers of sea bream fed 100FO, 60LO and 60Mix showed a regular morphology of hepatic tissue with hepatocytes of medium size. Livers of sea bream fed 60SO and 60RO showed more voluminous hepatocytes with the nucleus displaced to the cellular periphery. Sea bream fed $80 \mathrm{SO}$ and $80 \mathrm{LO}$ showed a tendency for accumulation of lipids in the hepatocytes and the peripancreatic tissue.
Table 5 Initial and final weight after short-term feeding of gilthead sea bream with diets containing different lipid sources

\begin{tabular}{lcl}
\hline \multicolumn{3}{c}{ Short-term experiment } \\
\cline { 2 - 3 } Diet & Initial weight $(\mathrm{g})$ & Final weight $(\mathrm{g})$ \\
\hline FO & $9.98 \pm 1.55$ & $65.38 \pm 9.28$ \\
SO & $10.11 \pm 1.56$ & $63.10 \pm 9.42$ \\
RO & $10.09 \pm 1.32$ & $68.58 \pm 11.50$ \\
LO & $10.07 \pm 1.59$ & $67.62 \pm 10.24$ \\
Mix & $10.07 \pm 1.45$ & $66.31 \pm 10.10$ \\
\hline
\end{tabular}

Table 6 Initial and final weight after long-term feeding with diets containing different lipid sources and washout periods for gilthead sea bream*

\begin{tabular}{llll}
\hline & \multicolumn{2}{l}{ Long-term experiment } & Washout period \\
\cline { 2 - 3 } Diet & Initial weight $(\mathrm{g})$ & Final weight $(\mathrm{g})$ & Final weight $(\mathrm{g})$ \\
\hline FO & $78.2 \pm 7.2$ & $463.9 \pm 50.2^{\mathrm{a}}$ & $689.8 \pm 95.6^{\mathrm{a}}$ \\
6OSO & $79.5 \pm 8.1$ & $457.1 \pm 49.7^{\mathrm{ab}}$ & $683.8 \pm 10.1^{\mathrm{a}}$ \\
6ORO & $79.7 \pm 7.6$ & $443.9 \pm 48.4^{\mathrm{ab}}$ & $665.2 \pm 105.7^{\mathrm{a}}$ \\
6OLO & $79.6 \pm 8.1$ & $461.1 \pm 53.8^{\mathrm{ab}}$ & $633.6 \pm 94.9^{\mathrm{ab}}$ \\
6OMix & $78.1 \pm 7.9$ & $451.6 \pm 9.7^{\mathrm{ab}}$ & $683.8 \pm 107.8^{\mathrm{a}}$ \\
8OSO & $79.0 \pm 8.2$ & $432.0 \pm 53.8^{\mathrm{b}}$ & - \\
8OLO & $78.4 \pm 8.3$ & $442.7 \pm 53.2^{\mathrm{b}}$ & $597.2 \pm 117.9^{\mathrm{b}}$ \\
\hline
\end{tabular}

${ }^{*}$ Different letters in the same column denote significant differences $(P<0.05)($ mean \pm SD) $(n=12)$.

After 6 months of feeding, the morphology of the livers from sea bream fed with different experimental diets was characterized by an increase in the cytoplasmic vacuolation, a marked nuclear displacement and in the severity of lipid infiltration (Table 8), irrespective of the diet (Fig. 2a-c).

\section{Histological examination and visual evaluation after the washout period}

Table 8 shows the evaluation of histological changes in fish fed in the washout period. After this feeding period, substantial changes in hepatic morphology were observed in the livers of fish fed different experimental diets. These changes were characterized by a considerable reduction of the cytoplasmic vacuolation, which allowed a clear visualization of the cell nucleus in a central position. However, there was an increase of the infiltration of peripancreatic fat (Fig. 3a-c).

\section{Fatty acid composition of livers in the short-term feeding trial}

Liver fatty acid composition clearly reflected the dietary lipids (Table 9). Livers of fish fed the FO 

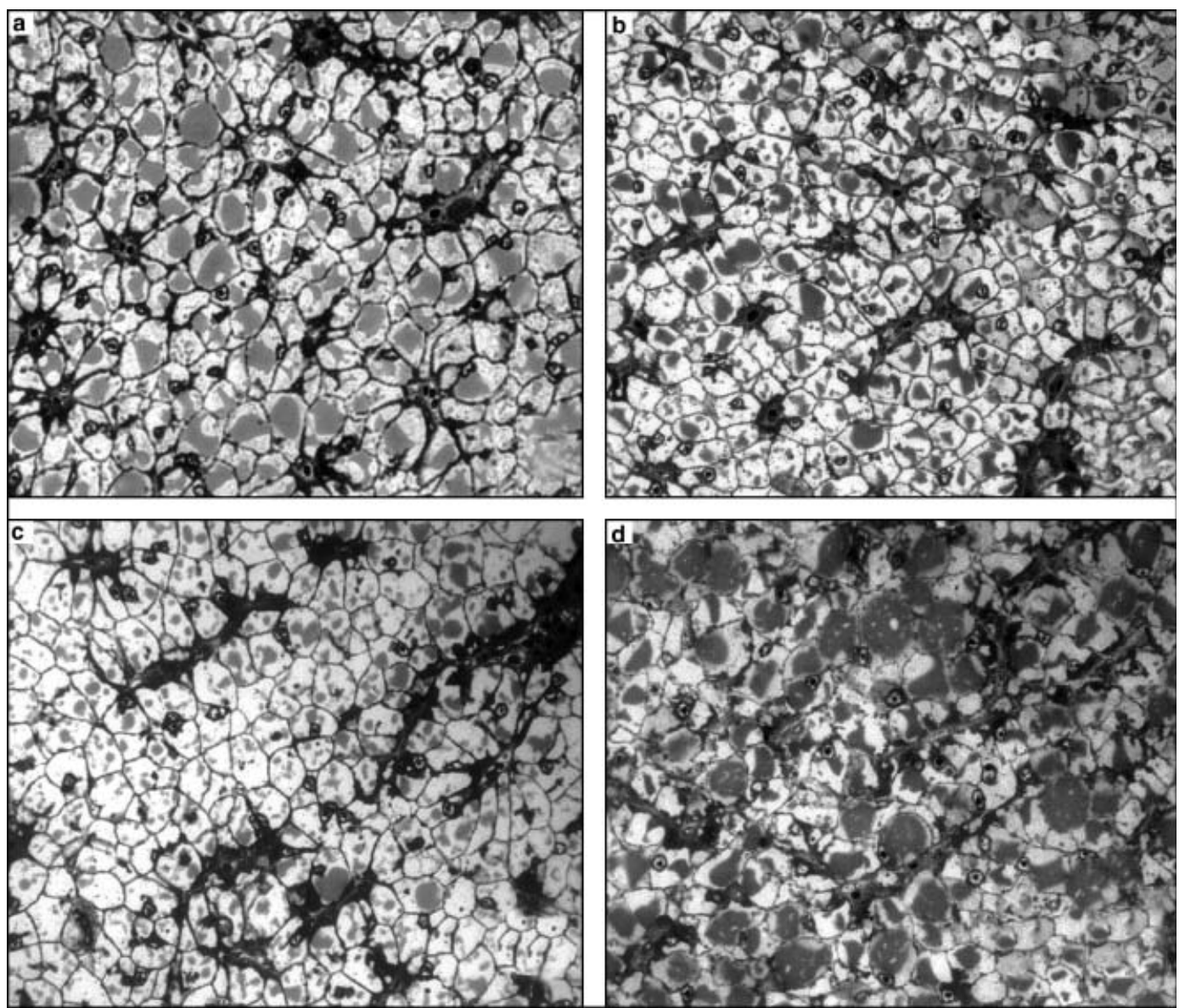

Figure 1 Livers of sea bream fed different experimental diets (short-term trial). (a) Control diet. Hepatocytes with large centrally located nuclei and some lipid vacuoles in the cytoplasm which do not significantly affect the size of the hepatocytes (TB\&BF, $\times 400$ ). (b) LO diet. Hepatocytes homogeneous in size with vacuolated cytoplasm similar to those found in the control diet (TB\&BF, $\times 400)$. (c) RO diet. Hepatocytes with few lipid vacuoles in the cytoplasm $(\mathrm{TB} \& \mathrm{BF}, \times 400)$. (d) SO diet. Foci of steatosis with hepatocytes containing numerous varying-size lipid vacuoles $(\mathrm{TB} \& \mathrm{BF}, \times 400)$.

Table 7 Short-term feeding trial. Volume density of hepatic lipid of livers from sea bream fed with the different experimental diets*

\begin{tabular}{ll}
\hline Diet & Lipid V/hepatocyte (\%) \\
\hline FO & $17 \pm 0.01^{\mathrm{ab}}$ \\
SO & $33 \pm 0.02^{\mathrm{c}}$ \\
RO & $11 \pm 0.01^{\mathrm{d}}$ \\
LO & $16 \pm 0.01^{\mathrm{a}}$ \\
Mix & $19 \pm 0.02^{\mathrm{b}}$ \\
\hline
\end{tabular}

${ }^{*}$ Different letters in the same column denote significant differences $(P<0.05)($ mean $\pm \mathrm{SD})(n=12)$.

diet were higher in saturated fatty acids and n-3 HUFA, and those of fish fed the $\mathrm{SO}, \mathrm{RO}$ and $\mathrm{LO}$ diets contained high levels of n-6, n-9 and n-3 fatty acids, respectively, whereas the liver fatty acid profile of fish fed the Mix diet more closely resembled the general profile of fish fed the FO diet. The n-3 HUFA content of liver of fish fed diets containing vegetable lipid sources showed a reduction in comparison with the levels found in fish fed the FO diet, resulting in relative reductions of about $48 \%$ (RO diet), 52\% (LO and Mix diet) and $58 \%$ (SO diet).

\section{Discussion}

In the present study, the hepatic morphology of fish fed linseed or a mixture of vegetable oils at a $60 \%$ substitution level was similar to that found in fish fed only FO. This might be related to the hypolipidaemic effect of linolenic acid as found in mammals. For instance, Rustan, Christiansen \& Drevon (1992) found that peroxisomal fatty acid oxidation in rats fed an LO-rich diet was not 
Table 8 Long-term feeding trial and washout period. Evaluation of histological changes in livers from sea bream fed different experimental diets $(n=12) .0=$ not observed; $1=$ few; $2=$ medium; $3=$ severe

\begin{tabular}{|c|c|c|c|c|c|c|c|}
\hline & \multicolumn{7}{|l|}{ Diet } \\
\hline & 100 & $\begin{array}{l}60 \\
50\end{array}$ & 60 & 60 & $\begin{array}{l}60 \\
\text { Mix }\end{array}$ & $\begin{array}{l}80 \\
50\end{array}$ & 80 \\
\hline \multicolumn{8}{|l|}{3 months feeding } \\
\hline Nuclear displacement & 1 & 2 & 2 & $1-2$ & $1-2$ & $1-2$ & 2 \\
\hline Cytoplasm vacuolated & 1 & 2 & 2 & 2 & $1-2$ & $1-2$ & 2 \\
\hline Peripancreatic fat & $1-2$ & 1 & 1 & 1 & 1 & 2 & $1-2$ \\
\hline \multicolumn{8}{|l|}{6 months feeding } \\
\hline Nuclear displacement & 3 & 3 & 3 & $2-3$ & 2 & 3 & 3 \\
\hline Cytoplasm vacuolated & 3 & 3 & 3 & 3 & 2 & 3 & 3 \\
\hline Peripancreatic fat & 1 & $1-2$ & $1-2$ & $1-2$ & $1-2$ & 2 & 2 \\
\hline \multicolumn{8}{|l|}{ Washout period } \\
\hline Nuclear displacement & 3 & $0-1$ & $0-1$ & $0-1$ & $0-1$ & $0-1$ & $0-1$ \\
\hline Cytoplasm vacuolated & 3 & 1 & 1 & 1 & 1 & 1 & 1 \\
\hline Peripancreatic fat & 1 & 2 & 2 & 2 & 2 & 3 & 3 \\
\hline
\end{tabular}

significantly different from that caused by feeding FO. Dietary alpha-18:3n-3 also significantly increased the mRNA levels of hepatic fatty acid oxidation enzymes including carnitine palmitoyltransferase I and II, mitochondrial, acyl-CoA oxidase and mitochondrial and peroxisomal 3-ketoacyl-CoA thiolases in rats (Ide 2000).

In contrast, an intense steatosis was observed in those fish fed SO. Kalogeropoulos, Alexis \& Henderson (1992) also described a high liver accumulation of $18: 2 n-6$, even in sea bream fed low linoleic acid levels. This could be related to the lipogenic effect of linoleic acid described in mammals, as diets rich in this fatty acid increase the fatty acid synthase and glucose-6-phosphate dehydrogenase activities (Ide 2000). Thus, Ikeda, Cha, Yanagita, Nakatani, Oogami, Imaizumi \& Yazama (1998) have shown that the concentration of serum and hepatic triacyglycerols is higher in rats fed a rich linoleic acid diet than those fed rich n-3 PUFA or linolenic acid diets. This effect might be also attributed to a lower oxidation capacity of linolenic acid. In both mitochondrial and peroxisomal pathways in rat liver homogenates, the palmitoyl-CoA oxidation rate was reduced by feeding oils rich in 18:2n-6 (Kabir \& Ide 1996; Kumamoto \& Ide 1998). In sea bream, recent enzymatic studies (Menoyo, Izquierdo, Robaina, Ginés, López-Bote \& Bautista 2004) have shown that the percentage of induced oxidation in livers of sea bream fed SO was 21 and $11 \%$ lower than in sea bream fed FO or LO, respectively. Larval studies (Izquierdo, Socorro, Arantzamendi \& HernándezCruz 2000) have also reported that the accumulation of lipid vacuoles in the basal zone of the enterocyte caused by feeding diets without lecithin supplementation disappeared when $0.1 \%$ phosphat- idylcholine (PC) was added to the diet regardless of its (squid or soybean) origin. However, squid PC was more efficient in reducing hepatic steatosis than soybean PC, denoting the lower $\beta$-oxidation of the 18:2n-6.

The low percentage of lipid vacuoles found in the livers of sea bream fed RO could be related to the reduced activity of the fatty acid synthase enzyme found in these livers $\left(0.057 \mathrm{IU} \mathrm{mg}^{-1}\right.$ protein) in comparison with that of fish fed FO (0.078 IU mg ${ }^{-1}$ protein) (M.J. Caballero, L. Robaina, D. Montero \& M.S. Izquierdo, unpublished data), as a consequence of high $18: 1 \mathrm{n}-9$ content in this diet. In mammals, oleic acid is known to have a similar hypolipidaemic effect to that of n-3 fatty acids, although to a lesser extent (Halvorsen, Rustan, Madsen, Reseland, Berge, Sletnes \& Christiansen 2001).

The increase in the cytoplasmic vacuolation, the marked nuclear displacement and the severity of lipid infiltration observed in the livers of sea bream after 6 months of feeding the experimental diets confirmed the tendency for accumulation of lipids in the livers of other cultured species (Shearer 1994; Wathne 1995). However, after the washout period feeding only FO, there was a reduction in the lipid content of the livers, with a decrease in the cytoplasmic vacuolation of the hepatocytes and a lower nuclear displacement, livers recovering their original morphology. These morphological changes are in agreement with the recovery of highly unsaturated fatty acids found in several tissues by M.S. Izquierdo, D. Montero, L. Robaina, M.J. Caballero, G. Rosenlund \& R. Ginés, unpublished data after this washout period. High intake of HUFAs (mainly EPA and DHA) prevents lipid accumulation as it induces lipid oxidation 

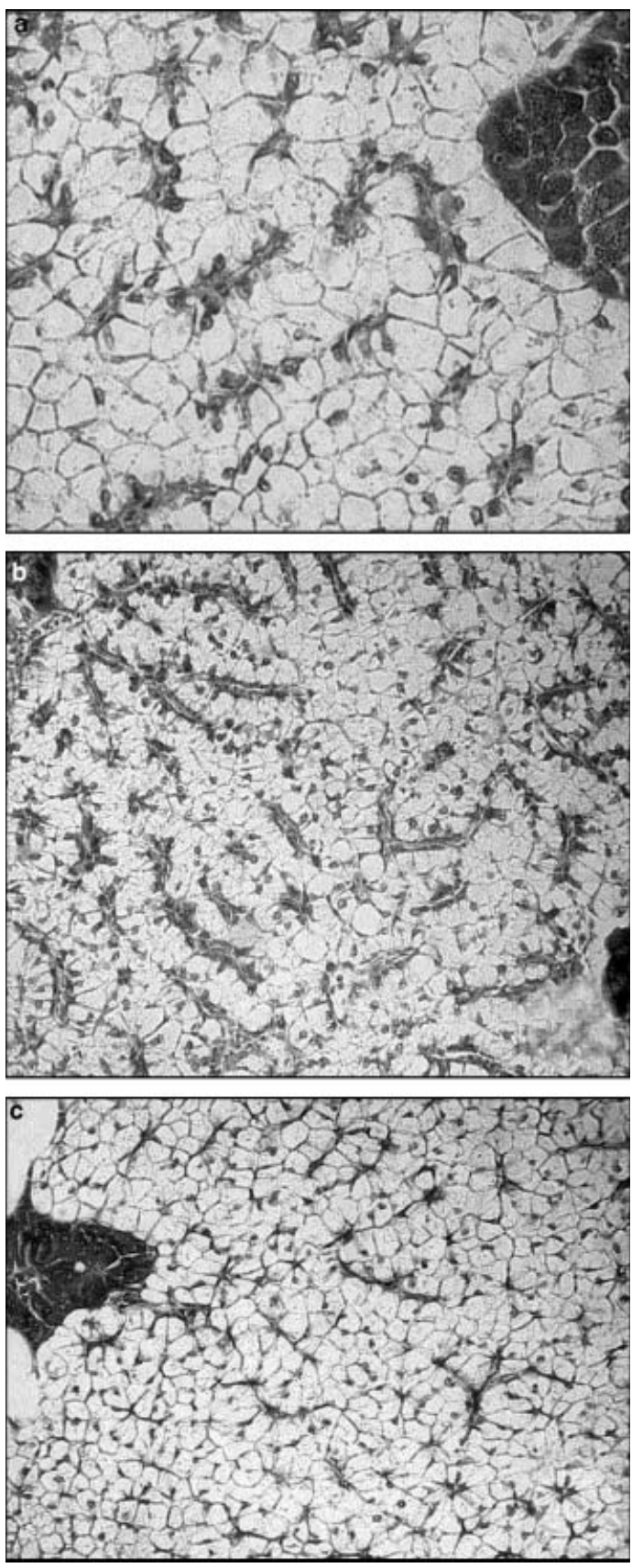

Figure 2 Livers of sea bream fed different experimental diets for 6 months (long-term trial), showing an increased cytoplasmic vacuolation, a marked nuclear displacement and severe lipid infiltration, irrespective of diet. (a) $60 \mathrm{SO}$ diet $(\mathrm{H} \& \mathrm{E}, \times 400)$, (b) $60 \mathrm{RO}$ diet $(\mathrm{H} \& \mathrm{E}, \times 200)$, (c) $80 \mathrm{SO} \operatorname{diet}(\mathrm{H} \& \mathrm{E}, \times 200)$.

through the activation of the peroxisomal $\beta$-oxidation (Duplus, Glorian \& Forest 2000; Clarke 2001), inhibits lipogenic metabolism (Shikata \& Shimeno 1994; Alvarez, Diez, López-Bote, Gallego
Table 9 Some fatty acids of livers of sea bream fed different vegetable lipid sources ( $\mathrm{g} 100 \mathrm{~g}^{-1}$ total fatty acids) after the short-term feeding trial

\begin{tabular}{lrrrrr}
\hline Diet & \multicolumn{1}{l}{ FO } & \multicolumn{1}{l}{ SO } & \multicolumn{1}{l}{ RO } & \multicolumn{1}{l}{ LO } & Mix \\
\hline Lipids (\% d. w.) & 29.82 & 30.20 & 33.13 & 30.17 & 29.6 \\
Fatty acid & & & & & \\
$\quad$ Saturated & 24.90 & 22.50 & 22.21 & 20.28 & 21.83 \\
18:1n-9 & 19.67 & 22.63 & 34.80 & 25.40 & 26.44 \\
18:2n-6 & 5.89 & 22.14 & 12.28 & 10.80 & 12.17 \\
18:3n-3 & 2.00 & 2.71 & 2.81 & 14.48 & 11.66 \\
20:4n-6 & 0.76 & 0.45 & 0.40 & 0.45 & 0.42 \\
20:5n-3 & 7.59 & 4.31 & 3.62 & 3.98 & 3.87 \\
22:6n-3 & 11.25 & 6.58 & 5.44 & 5.88 & 5.75 \\
n-3 HUFA & 18.84 & 10.89 & 9.06 & 9.86 & 9.62 \\
18:1n-9/DHA & 1.75 & 3.44 & 6.40 & 4.32 & 4.60 \\
\hline
\end{tabular}

\& Bautista 2000; Regost et al. 2003; Menoyo et al. 2004) and stimulates lipoprotein synthesis (Watanabe 1982). On the other hand, EPA is considered a major hypotriglyceridaemic component of $\mathrm{FO}$ as it increases mitochondrial fatty acid oxidation in rats (Frøyland, Madsen, Vaagenes, Totland, Auwex, Kryvi, Staels \& Berge 1997; Madsen, Rustan, Vaagenes, Berge, Dyroy \& Berge 1999). Thus, morphological studies have revealed that EPA increases the area fraction of both mitochondria and peroxisomes, reducing the number of lipid droplets in the liver (Frøyland, Helland, Totland, Kryvi \& Berge 1996; Totland, Madsen, Klementsen, Vaagenes, Kryvi, Frøyland, Hexeberg \& Berge 2000). In addition, EPA decreases the availability of fatty acid for TG synthesis, reducing the diacylglycerol acyltransferase (DGAT) activity (Berge, Madsen, Vaagenes, Tronstad, Gottlicher \& Rustan 1999). Therefore, the decrease of the lipid content, and the reduction of the cytoplasmic vacuolation and nuclear displacement observed in the livers of the washout period could be a consequence of the metabolic actions associated with the EPA and DHA acids. Enzymatic analyses are being conducted to elucidate the metabolic effects of these fatty acids in sea bream.

In summary, the results of this study confirm that the reduction of the dietary essential fatty acids due to the inclusion of vegetable oils in the diets tends to promote fat accumulation in the livers of sea bream. However, not only the reduction of essential fatty acids in diets but also the type of non-essential fatty acid included in the diet seems to affect the hepatic morphology. Thus, it is possible to establish an order between the characteristic fatty acids of the vegetable oils and the appearance of steatosis, i.e. linoleic acid > linolenic acid > oleic acid. Finally, 

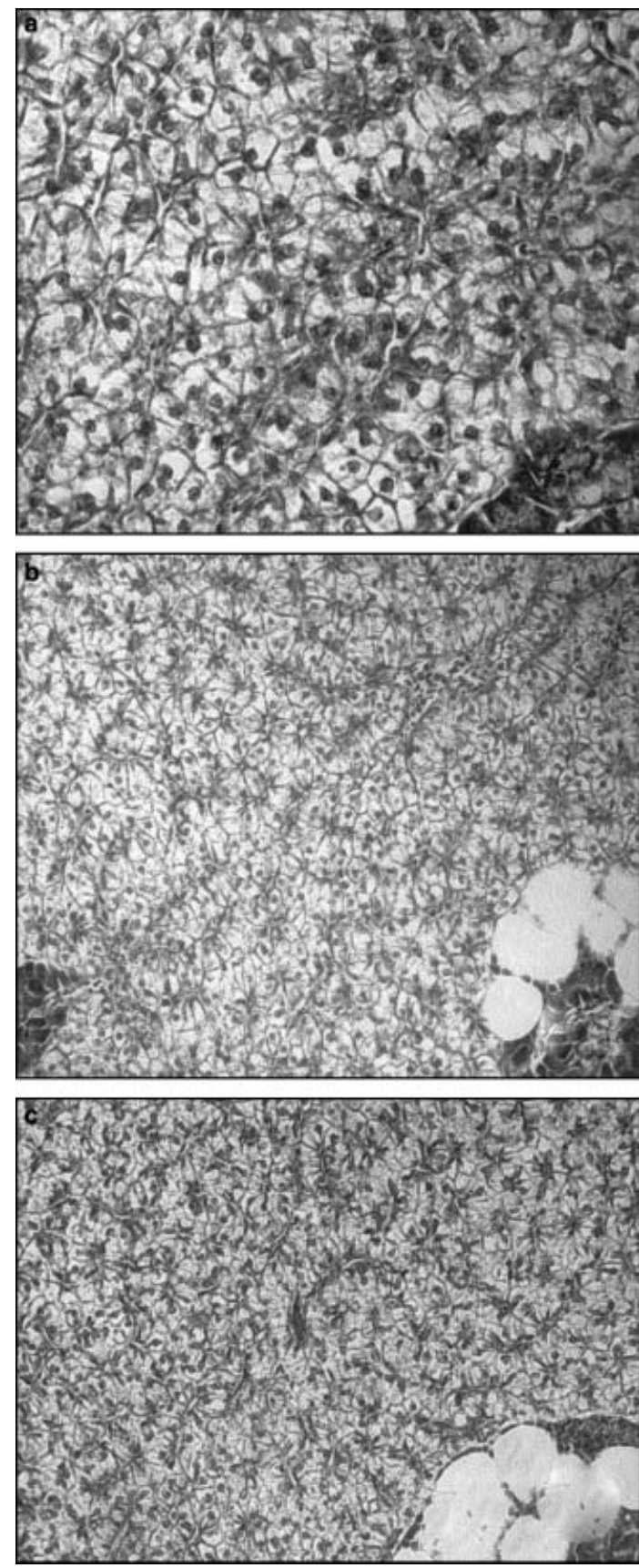

Figure 3 Livers of sea bream after washout period. Hepatic morphology is characterized by a considerable reduction of the cytoplasmic vacuolation which allows a clear visualization of the cell nucleus in a central position. (a) $60 \mathrm{SO}$ diet $(\mathrm{H} \& \mathrm{E}, \times 400)$, (b) 60RO diet (H\&E, $\times 200)$, (c) $80 \mathrm{SO}$ diet $(\mathrm{H} \& \mathrm{E}, \times 200)$.

the results show that the morphological alterations found in the livers are reversible when the fish are re-fed with a balanced diet, denoting the nonpathological character of these liver alterations.

\section{Acknowledgements}

This study was partially supported by research grants from the EU and the Spanish Government under the FEDER programme, project no. 1FD1997-1774 and from the European Union under 'Quality of Life and Management of Living Resources' through the project Q5RS-2000-30058 'RAFOA'. M.J. Caballero was in receipt of a grant from the Spanish Ministerio de Educación, Cultura y Deportes.

\section{References}

Alexis M.N. (1997) Fish meal and fish oil replacers in Mediterranean marine fish diets. Cahiers Options Méditerranéennes 22, 183-204.

Alvarez M.J., Diez A., López-Bote C.J., Gallego M. \& Bautista J.M. (2000) Short-term modulation of lipogenesis by macronutrients in rainbow trout (Oncorhynchus mykiss) hepatocytes. British Journal of Nutrition 84, 619-628.

Angermüller S. \& Dariush Fahimi H. (1982) Imidazole-buffered osmium tetroxide: an excellent stain for visualization of lipids in transmission electron microscopy. The Histochemical Journal 14, 823-835.

Bell J.G., McGhee F., Campbell P.J. \& Sargent J.R. (2003) Rapeseed oil as an alternative to marine fish oil in diets of post-smolt Atlantic salmon (Salmo salar): changes in flesh fatty acid composition and effectiveness of subsequent fish oil 'wash out'. Aquaculture 218, 515-528.

Berge R.K., Madsen L., Vaagenes H., Tronstad K.J., Gottlicher M. \& Rustan A.C. (1999) In contrast with docosahexaenoic acid, eicosapentanoic acid and hypolipidaemic derivatives decrease hepatic synthesis and secretion of triacylglycerol by decreased diacylglycerol acyltransferase activity and stimulation of fatty acid oxidation. Biochemical Journal 343, 191-197.

Caballero M.J., López-Calero G., Socorro J., Roo F.J., Izquierdo M.S. \& Fernández A.J. (1999) Combined effect of lipid level and fish meal quality on liver histology of gilthead sea bream (Sparus aurata). Aquaculture 179, 277-290.

Caballero M.J., Obach A., Rosenlund G., Montero D., Gisvold M. \& Izquierdo M.S. (2002) Impact of different dietary lipid sources on growth, lipid digestibility, tissue fatty acid composition and histology of rainbow trout, Oncorhynchus mykiss. Aquaculture 214, 253-271.

Christie W.W. (1982) Lipid Analysis. Pergamon Press, Oxford.

Clarke S.D. (2001) Nonalcoholic steatosis and steatohepatitis. 1. Molecular mechanism for polyunsaturated fatty acid regulation of gene transcription. American Journal of Physiology - Gastrointestinal and Liver Physiology 281, 865-869.

Duplus E., Glorian M. \& Forest C. (2000) Fatty acid regulation of gene transcription. Journal of Biological Chemistry 275, 30749-30752.

FAO (1997) Review of the State of the World Aquaculture. FAO Fisheries Circular No. 886. Rev. 1. FAO, Rome, 163 pp. 
Folch J., Lees M. \& Sloane-Stanley G.H. (1957) A simple method for the isolation and purification of total lipids from animal tissues. Journal of Biological Chemistry 226, 497-509.

Fox C. (1990) Studies on polyunsaturated fatty acid nutrition in larvae of marine fish-the herring, Clupea harengus $L . \mathrm{PhD}$ Thesis. University of Stirling, UK, 196 pp.

Frøyland L., Helland K., Totland G.K., Kryvi H. \& Berge R.K. (1996) A hypolipidemic peroxisome proliferating fatty acid induces polydispersity of rat liver mitochondria. Biology of the Cell 87, 105-112.

Frøyland L., Madsen L., Vaagenes H., Totland G.K., Auwex J., Kryvi H., Staels B. \& Berge R.K. (1997) Mitochondrion is the principal target for nutritional and pharmacological control of triglyceride metabolism. Journal of Lipid Research 38, 1851-1858.

Halvorsen B., Rustan A.C., Madsen L., Reseland J., Berge R.K., Sletnes P. \& Christiansen E.N. (2001) Effects of long-chain monounsaturated and n-3 fatty acids on fatty acid oxidation and lipid composition in rats. Annals of Nutrition \& Metabolism 45, 30-37.

Henderson R.J. (1996) Fatty acid metabolism in freshwater fish with particular reference to polyunsaturated fatty acids. Archives of Animal Nutrition 49, 5-22.

Hoffman E.O., Flores T.R., Coover J. \& Garrett H.B. (1983) Polychrome stains for high resolution light microscopy. Laboratory Medicine 14, 779-781.

Ide T. (2000) Effect of dietary alpha-linolenic acid on the activity and gene expression of hepatic fatty acid oxidation enzymes. Biofactors 13, 9-14.

Ikeda I., Cha J.Y., Yanagita T., Nakatani N., Oogami K., Imaizumi K. \& Yazama K. (1998) Effects of dietary alphalinolenic, eicosapentaenoic and docosahexaenoic acids on hepatic lipogenesis and $\beta$-oxidation in rats. Bioscience Biotechnology and Biochemistry 62, 675-680.

Izquierdo M.S., Watanabe T., Takeuchi T., Arakawa T. \& Kitajima C. (1990) Optimum EFA levels in artemia to meet the EFA requirements of red sea bream (Pagrus major). In: The Current Status of Fish Nutrition in Aquaculture (ed. by M. Takeda \& T. Watanabe), pp. 221-232. University of Fisheries, Tokyo.

Izquierdo M.S., Socorro J., Arantzamendi L. \& Hernández-Cruz C.M. (2000) Recent advances in lipid nutrition in fish larvae. Fish Physiology and Biochemistry 22, 97-107.

Izquierdo M.S., Obach A., Arantzamendi L., Montero D., Robaina L. \& Rosenlund G. (2003) Dietary lipid sources for sea bream and sea bass: growth performance, tissue composition and flesh quality. Aquaculture Nutrition 9, 397-407.

Kabir Y. \& Ide T. (1996) Activity of hepatic fatty acid oxidation enzymes in rats fed alpha-linolenic acid. Biochimica et Biophysica Acta 1304, 105-119.

Kalogeropoulos N., Alexis M.N. \& Henderson R.J. (1992) Effects of dietary soybean and cod-liver oil levels on growth and body composition of gilthead sea bream (Sparus aurata). Aquaculture 104, 293-308.

Kaushik S.J. (1997) Recent developments in the nutrition and feeding of marine finfish of interest to the Mediterranean. Communication at INVE Conference Nutritional and the improvement of the sea bass and sea bream production in the
Mediterranean Region. ALIIA Trades Show, Thessaloniki, Greece.

Kiessling K.H. \& Kiessling A. (1993) Selective utilization of fatty acids in rainbow trout (Oncorhynchus mykiss Walbaum) red muscle mitochondria. Canadian Journal of Zoology 71, 248-251.

Kumamoto T. \& Ide T. (1998) Comparative effects of alphaand gamma-linolenic acids on rat liver fatty acid oxidation. Lipids 33, 647-654.

Lie Ø., Lied E. \& Lambertsen G. (1986) Liver retention of fat and of fatty acids in cod (Gadus morhua) fed different oils. Aquaculture 59, 187-196.

Madsen L., Rustan A.C., Vaagenes H., Berge K., Dyroy E. \& Berge R.K. (1999) Eicosapentaenoic and decosahexaenoic acid affect mitochondrial and peroxisomal fatty acid oxidation in relation to substrate preference. Lipids 34, 951-963.

Martoja R. \& Martoja-Pierson M. (1970) Técnicas de Histología Animal. Ed. Toray-Masson S.A., Barcelona, 350 pp.

Menoyo D., Izquierdo M.S., Robaina L., Ginés R., López-Bote C.J. \& Bautista J.M. (2004) Adaptation of lipid metabolism, tissue composition and flesh quality in gilthead sea bream (Sparus aurata) to the fish oil replacement by linseed and soybean oils. British Journal of Nutrition 92, 41-52.

Montero D., Tort L., Izquierdo M.S., Socorro J., Robaina L.E., Vergara J.M. \& Fernández-Palacios H. (1996) Effect of alphatocopherol and n-3 HUFA deficient diets on blood cells, selected immune parameters and proximate body composition of gilthead sea bream (Sparus aurata). In: Modulators of Immune Response. The Evolutionary Trail 9 (ed. by J.S. Stolen, T.C. Fletcher, C.J. Bayne, C.J. Secombes, J.L. Zelikoff, L. Twerdock \& D.P. Anderson), pp. 251-266. S.O.S. Publications, Fair Haven.

Montero D., Robaina L.E., Socorro J., Vergara J.M., Tort L. \& Izquierdo M.S. (2001) Alteration of liver and muscle fatty acid composition in gilthead sea bream (Sparus aurata) juveniles held at high stocking density and fed an essential fatty acid deficient diet. Fish Physiology and Biochemistry 24, 63-72.

Mosconi-bac N. (1990) Reversibility of artificial feed-induced hepatocyte disturbances in cultured juvenile sea bass (Dicentrarchus labrax): an ultrastructural study. Aquaculture 88, 363-370.

NRC (1993) Nutritional Requirements of Fish. National Academic Press, Washington, DC.

Regost C., Arzel J., Robien J., Rosenlund G. \& Kaushik S.J. (2003) Total replacement of fish oil by soybean or linseed oil with a return to fish oil in turbot (Psetta maxima) 1. Growth performance, flesh fatty acid profile, and lipid metabolism. Aquaculture 217, 465-482.

Rustan A.C., Christiansen E.N. \& Drevon C.A. (1992) Serum lipids, hepatic glycerolipid metabolism and peroxisomal fatty acid oxidation in rats fed omega- 3 and omega- 6 fatty acids. Biochemical Journal 283, 333-339.

Segner H. \& Witt U. (1990) Weaning experiments with turbot (Scophthalmus maximus): electron microscopic study of liver. Marine Biology 105, 353-361.

Shearer K.D. (1994) Factors affecting the proximate composition of cultured fishes with emphasis on salmonids. Aquaculture 119, 63-88. 
Journal of Fish Diseases 2004, 27, 531-541 M J Caballero et al. Histological alterations in the liver of sea bream, Sparus aurata $L$.

Shikata T. \& Shimeno S. (1994) Metabolic response to dietary stearic acid, linoleic acid, and highly unsaturated fatty acid in carp. Fisheries Science 60, 735-739.

Sokal R.R. \& Rolf F.J. (1995) Biometry. The Principles and Practice of Statistics in Biological Research. W.H. Freeman \& Co., New York.

Spisni E., Tugnoli M., Ponticelli A., Mordenti T. \& Tomasi V. (1998) Hepatic steatosis in artificially fed marine teleosts. Journal of Fish Diseases 21, 177-184.

Tacon A.G.J. (1996) Lipid nutritional pathology in farmed fish. Archives of Animal Nutrition 49, 33-39.

Totland G.K., Madsen L., Klementsen B., Vaagenes H., Kryvi H., Frøyland L., Hexeberg S. \& Berge R.K. (2000) Proliferation of mitochondria and gene expression of carnitine palmitoyltransferase and fatty acid acyl-CoA oxidase in rat skeletal muscle, heart and liver by hypolipidemic fatty acids. Biology of the Cell 92, 317-329.

Watanabe T. (1982) Lipid nutrition in fish. Comparative Biochemistry and Physiology 73B, 3-15.

Wathne E. (1995) Strategies for directing slaughter quality of farmed Atlantic salmon (Salmo salar) with emphasis on diet composition and fat deposition. PhD Thesis, University of Tromso, Norway.

Weibel E.R. (1979) Stereological Methods, Vol. 1. Academic Press, New York.

Received: 27 January 2004

Revision received: 20 May 2004

Accepted: 14 June 2004 